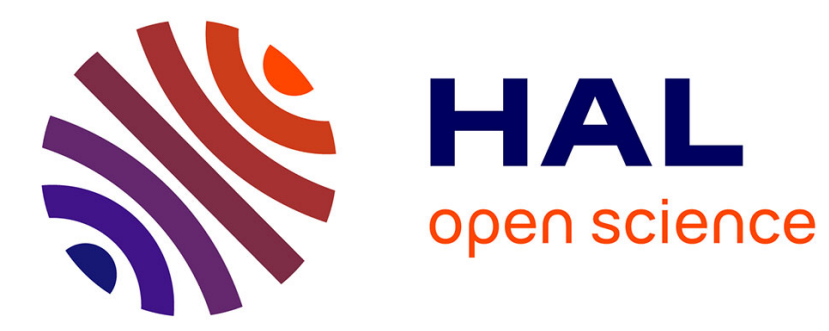

\title{
Transformation Mechanism of Deformation - Induced Compact Martensite in Fe-Ni-C Alloys
}

\author{
X. Zhang, T. Hu, X. Meng, Y. Li, E. Gautier, J. Zhang
}

\section{To cite this version:}

X. Zhang, T. Hu, X. Meng, Y. Li, E. Gautier, et al.. Transformation Mechanism of Deformation Induced Compact Martensite in Fe-Ni-C Alloys. Journal de Physique IV Proceedings, 1995, 05 (C8), pp.C8-317-C8-322. 10.1051/jp4:1995845 . jpa-00254094

\section{HAL Id: jpa-00254094 https://hal.science/jpa-00254094}

Submitted on 1 Jan 1995

HAL is a multi-disciplinary open access archive for the deposit and dissemination of scientific research documents, whether they are published or not. The documents may come from teaching and research institutions in France or abroad, or from public or private research centers.
L'archive ouverte pluridisciplinaire HAL, est destinée au dépôt et à la diffusion de documents scientifiques de niveau recherche, publiés ou non, émanant des établissements d'enseignement et de recherche français ou étrangers, des laboratoires publics ou privés. 


\title{
Transformation Mechanism of Deformation - Induced Compact Martensite in Fe-Ni-C Alloys
}

\author{
X.M. Zhang, T.R. Hu, X.M. Meng, Y.Y. Li, E. Gautier* and J.S. Zhang* \\ Laboratory of Atomic Imaging of Solids, Institute of Metal Research, Academia Sinica, Shenyang, \\ 110015, China \\ * Laboratoire de Science et Génie des Matériaux Métalliques, URA 159 du CNRS, Ecole des Mines, Parc \\ de Saurupt, 54042 Nancy cedex, France
}

\begin{abstract}
Compact deformation - induced martensite found in $\mathrm{Fe}-25 \mathrm{Ni}-0.66 \mathrm{C}$ alloys has been studied by using optical, electron and scanning electron microscopy. The compact martensite consists of a large number of martensites with different variants connected closely to form large bulk in which almost no residual austenite remains. Its formation process is by further growth of thin plates to form lenticular plates and possible crossing and coalesence to form bulky martensite. These growth and coalesence are through martensitic twinning or twinning domains during deformation which leads to various interactions between the plates including cross, insert, coalescence and conversion. The substructure of the martensite is a crisscross twinning net. The corresponding deformation modes of the austenite are also studied.
\end{abstract}

\section{INTRODUCTION}

A series of investigations on morphology transitions of deformation - induced martensites have been performed in $\mathrm{Fe}-\mathrm{Ni}$ and $\mathrm{Fe}-\mathrm{Ni}-\mathrm{C}$ alloys $[1-4]$. With the increase of tensile deformation level, different types of deformation - induced martensites were found. In addition to $(111)_{\mathrm{f}}$ butterfly martensite, couples of self accommodating thin plates and lenticular couples of self accommodating martensites, compact (or massive) martensites were found in $\mathrm{Fe}-30 \mathrm{Ni}$ and $\mathrm{Fe}-25 \mathrm{Ni}-0$. 66C alloys ${ }^{1}$. For the $\mathrm{Fe}-30 \mathrm{Ni}$ alloy, transitions in morphology were observed with progressive deformation levels going from lenticular to butterfly and to compact martensites. The deformation - induced butterfly martensites with different $\{111\}_{f}$ habit planes were conjugated closely to form the compact martensite in which the substructure was high densities of dislocations and no residual austenites were found between the conjunctive plates[3]. For the $\mathrm{Fe}-25 \mathrm{Ni}-$ 0 . 66C alloy, morphology transitions from thin plate to lenticular and to compact martensite were observed [4]. This compact martensite consisted of many plates which were also connected closely to form large bulk. However, its substructure and formation process are not clear. The purpose of the present work is to study the formation mechanism of the compact martensite and the deformation modes of the austenite.

\section{EXPERIMENTAL PROCEDURE}

Three alloys, $\mathrm{Fe}-25 \mathrm{Ni}-0.66 \mathrm{C}, \mathrm{Fe}-30 \mathrm{Ni}-0.25 \mathrm{C}$ and $\mathrm{Fe}-30 \mathrm{Ni}-0.34 \mathrm{C}$, were selected in order to investigate the formation of compact martensites. Specimens were austenitized at $1100^{\circ} \mathrm{C}$ for $30 \mathrm{~min}$, and then quenched to room temperature. The $\mathrm{M}_{\mathrm{s}}$ temperature were respectively $-153^{\circ} \mathrm{C},-88^{\circ} \mathrm{C}$, and $-208^{\circ} \mathrm{C}$. The mean grain size of the specimen is about $65 \mu \mathrm{m}$ for $\mathrm{Fe}-25 \mathrm{Ni}-0.66 \mathrm{C}$ alloy. Tensile tests were carried out at a constant temperature between $M_{s}$ and $M_{d}$ on a Shimadzu Autograph DSC-10tons and or on a thermomechanical simulator Dithem. The specimens were cut parallel and perpendicular to the tensile direction. The microstructure of the alloys were studied by optical, transmission electron and scanning electron microscopy.

1 Al compositions are given in ut \% 


\section{RESULTS and DISCUSSION}

\subsection{Optical micrography}

The morphology of deformation-induced martensite in $\mathrm{Fe}-30 \mathrm{Ni}-0.25 \mathrm{C}$ alloy is lenticular. The martensite plates become thinner in width than those of thermally transformed without applied stress, and tend to have an identical orientation. When the deformation is increased up to $31 \%$ in tension at a higher temperature $\mathrm{M}_{\mathrm{S}}+48^{\circ} \mathrm{C}\left(\mathrm{M}_{\mathrm{S}}=-\right.$ $88^{\circ} \mathrm{C}$ ), the martensite plates are likely connected to form a "compact martensite" in which the residual austenite still remains between the plates, as indicated by arrows in figure 1 (a). Around the "compact martensite", three deformation twinning systems designated by I, II and III in figure 1(a) were operating in the austenite under external applied stress. It implied that the austenitic grain was locally rotated and in the local region around the rotation center, new variants of martensite with favourable orientation were easily induced. As a result, many plates with different orientations were connected and concentrated in the rotation region, as indicated by the large arrows in figure $1(\mathrm{a})$.

Similar results were found in $\mathrm{Fe}-25 \mathrm{Ni}-0.66 \mathrm{C}$ alloy. As shown in figure $1(\mathrm{~b})$, three deformation twinning systems were operating in the austenite as labeled by I, II , III and some compact martensites labeled by $\mathrm{A}$ were induced. Beyond the deformation twinning region in the austenite, individual lenticular martensites can be found, as labeled by $B$ in the figure.

Figure $1(c)$ is a typical morphology of the deformation - induced compact martensite in $\mathrm{Fe}-25 \mathrm{Ni}-0.66 \mathrm{C}$ alloy. This compact martensite consists of many plates connected closely even crossing each other to form rectangular bulks. Figure 1(d) shows an intermediate stage of the formation of a compact martensite in the same alloy. This magnified microstructure is similar to the one labeled by $\mathrm{A}$ in figure $1(\mathrm{~b})$. It is noted that the compact martensite was formed through the morphology transitions from thin plate to lenticular and to bulky martensites. The lenticular plates as indicated by arrows in figure 1(d) which present an internal part similar to the thin plates can be considered as formed from the thin plates and inherited the chracteristics of the thin plates. Therefore, this type of lenticular plates can cross and coalesce with each other. All these features can be observed in figure $1(d)$.

\subsection{Transmission electron microscopy}

Figure $2(\mathrm{a})$ is a dark field image obtained by TEM showing a lenticular couple of self accommodating martensite plates named lenticular couply - plate obtained by deformation in $\mathrm{Fe}-30 \mathrm{Ni}-0.34 \mathrm{C}$ alloy[3]. In the right variant of the lenticular couple-plate, some transfornation twinning bands seem to have extended into the austenite when the plate has further grown. Marks A and B could represent respectively a first and second step of the plate growth. In this case, each band consists of about 5 pre-existed fine transformation twins. These twinning bands can be explained as deformation twinning of martensite induced by external applied stress. The similar growth of thin plate by twinning bands was also found in $\mathrm{Fe}-25 \mathrm{Ni}-0.66 \mathrm{C}$ alloy, and new thin plates, parallel with the twinning bands were induced, as shown in figure $2(\mathrm{~b})$.

We have shown in figure 1 (d) that for $\mathrm{Fe}-25 \mathrm{Ni}-0.66 \mathrm{C}$ alloy, the plates were able to cross each other. Figure $3(\mathrm{a})$ shows such a crossing: one plate $A$ has a sidewise distribution of transformation twins and the other plate $B$ has a longitudinal distribution of transformation twins. In the crossing area, a complex substructure of domains is observed. A series of domains forming spair inside the crossing area, named couple - domains were induced in the plate $B[5]$, as denoted by letters $a, b, c, d$, e and $f$ etc. in figure 3 . From the electron diffraction pattern figure $3(\mathrm{~b})$ taken from the crossed region and the dark field (DF) images figure $3(\mathrm{c})$ and (d) taken from spots $(200)_{b}$ and $(200)_{b t}$ respectively, it was found that the parallel couple - domains are twin related. They can be considered as self - accommodating domains and they have the same orientation as do- 

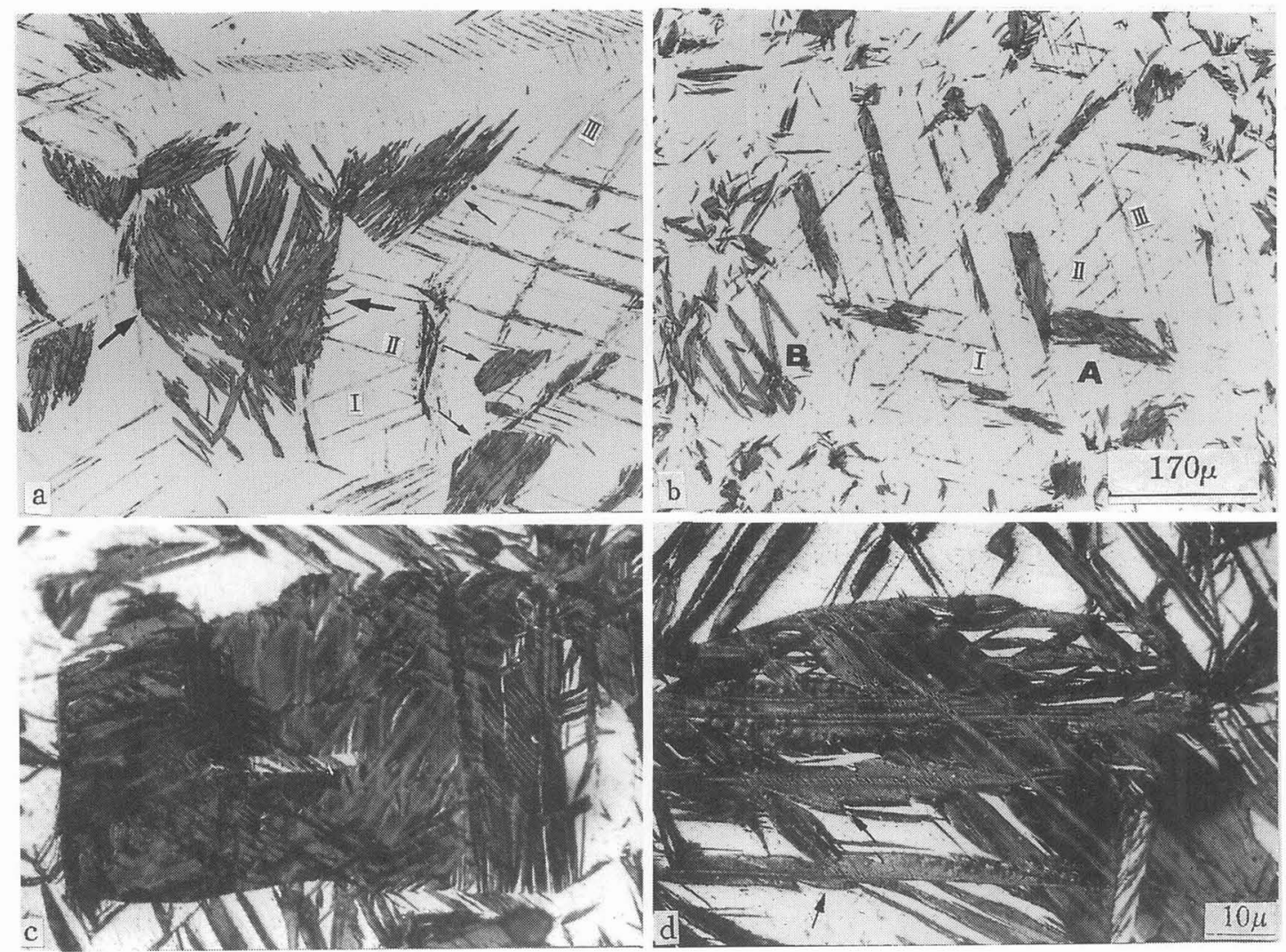

Figure 1. Optical micrographs showing deformation - induced "compact martensites" and deformation twinning of austenite. (a) deformed at $-40^{\circ} \mathrm{C}\left(\mathrm{Ms}=-88^{\circ} \mathrm{C}\right), \varepsilon=31 \%$ in $\mathrm{Fe}-30 \mathrm{Ni}-0.25 \mathrm{C}$, (b)at $-80 \mathrm{C}\left(\mathrm{Ms}=-153^{\circ} \mathrm{C}\right)$, $\varepsilon=8 \%(\mathrm{c})$ and $(\mathrm{d})$ at $-120^{\circ} \mathrm{C}\left(\mathrm{Ms}+33^{\circ} \mathrm{C}\right), \varepsilon=10 \%$ in $\mathrm{Fe}-25 \mathrm{Ni}-0.66 \mathrm{C}$

mains in plate $A$. As shown on the DF images figure $3(c)$ and (d), the domains in plate $A$ are also twin related and connect with the couple-domains in plate $B$ on the $A-B$ junction plane. Each domains in plate A contains 5 to 15 fine transformation twins as increasing number of twins going from a to $f$ corresponding to the growth of couple domains of plate $B$.

An increase in the thin plate width was clearly shown for the $\mathrm{Fe}-25 \mathrm{Ni}-0.66 \mathrm{C}$ alloy transformed during deformation or during cooling under stress[6]. Variations of the internal distribution of transformation twins during the plate growth have been reported previously by Roytburd and Pankova for stress - induced martensite formed in $\mathrm{Fe}-\mathrm{Ni}-\mathrm{C}$ alloys[7]. On the basis of the thermodynamics analysis of martensitic transformation under stress, the authors predicted and observed a new equilibrium substructure i. e. a new distribution of the transformation twins if the transformation occurs under stress. The formation of bands that we observe can thus be related to the change in the transformation twin distribution as martensite forms under stress. In Roytburd theoritical analysis, the interfaces between twins are mobile and the plate tends to reach an equilibrium substructure. The continuous change in twin distribution observed along the plate width can be related to a change of the stress state near the martensite / austenite interface when the plate thickens. This means also that the twin distribution of martensite transformed during cooling under stress is not considerably modified inside the plate during the further plate growth.

The "compact" martensite can be considered as a group of thin plates which have thickened and which are able to cross each other, this crossing being favoured when plates are formed under stress. Crossing of thin plates was observed by Okamoto et al[8] in 


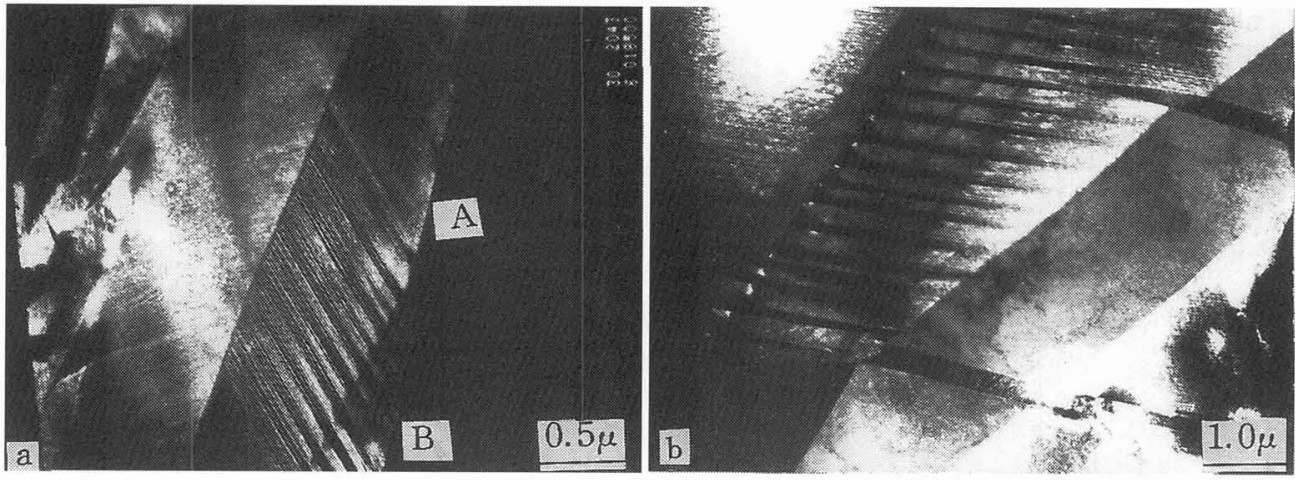

Figure 2. Electron micrographs showing deformation twinning of martensite (a) deformed at $-196^{\circ} \mathrm{C}\left(\mathrm{Ms}=-208^{\mathrm{C}} \mathrm{C}\right)$, $\varepsilon=8 \%$ in $\mathrm{Fe}-30 \mathrm{Ni}-0.34 \mathrm{C}$, (b) at $-130 \mathrm{C}\left(\mathrm{Ms}+23^{\circ} \mathrm{C}\right), \varepsilon=6 \%$ in $\mathrm{Fe}-25 \mathrm{Ni}-0.66 \mathrm{C}$
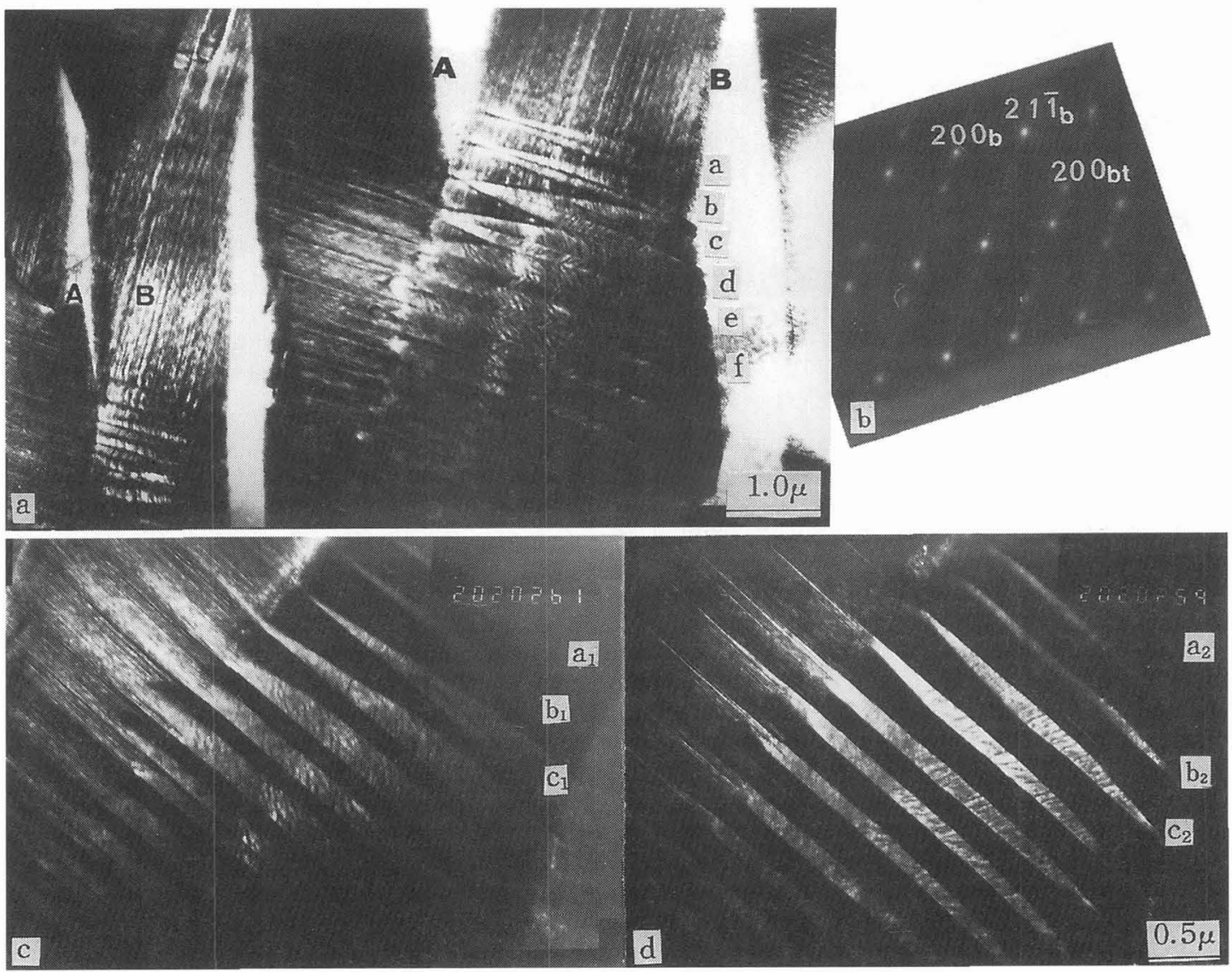

Figure 3. Electron micrographs showing conversion process between variants deformed at $-130^{\circ} \mathrm{C}(\mathrm{Ms}=-153 \mathrm{C})$, $\epsilon=6 \%$ in $\mathrm{Fe}-25 \mathrm{Ni}-0.66 \mathrm{C}$ (a) BF image, (b) diffraction pattern, (c) and (d) DF image in the same area. 


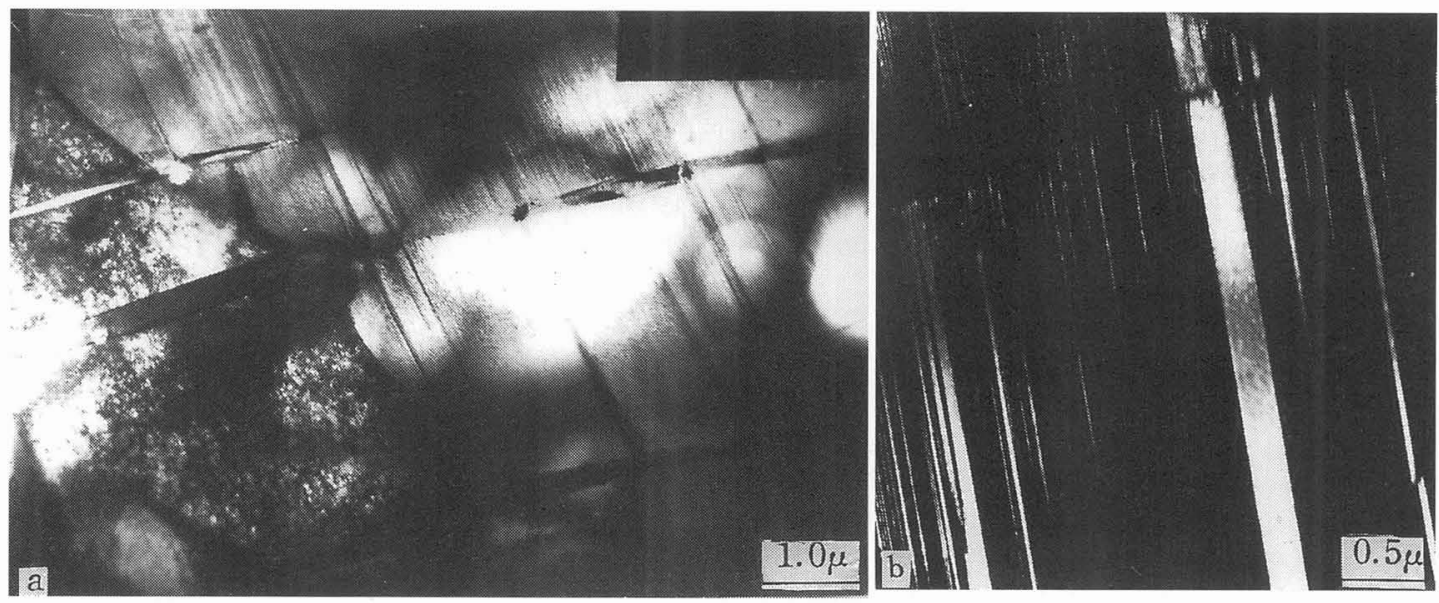

Figure 4. Electron micrographs showing thin plates insert a large lenticular plate deformed at $-100 \hat{\mathrm{U}}(\mathrm{Ms}=-153 \hat{\mathrm{C}})$, $\varepsilon=8 \%$ in $\mathrm{Fe}-25 \mathrm{Ni}-0.66 \mathrm{C}$ (a) bright field image, (b) dark field image.
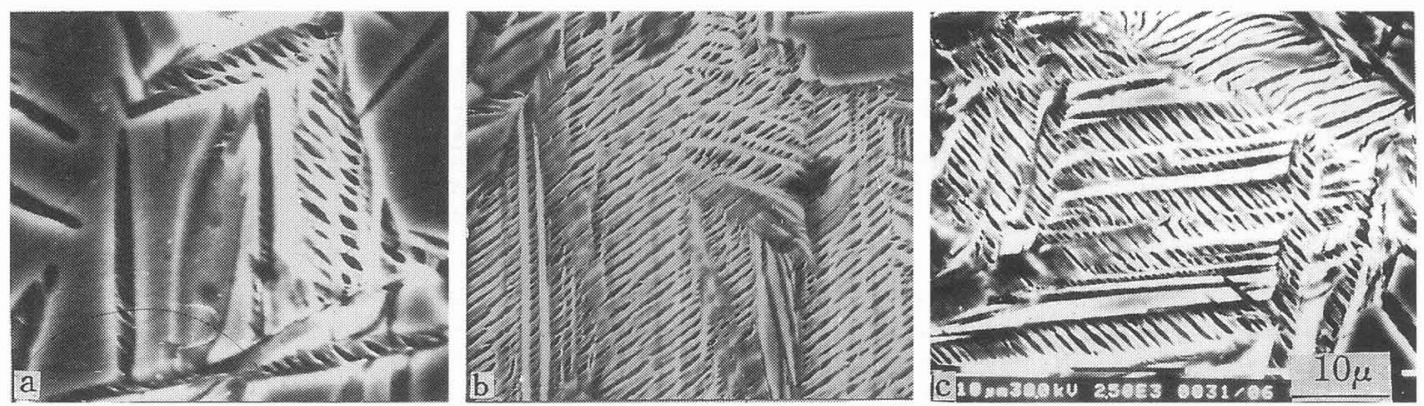

Figure 5. Scanning electron micrographs showing morphology transition, variant conversion, insert and cross, de formed at $-120^{\circ} \mathrm{C}(\mathrm{Ms}=-153 \mathrm{C}), \varepsilon=10 \%$ in $\mathrm{Fe}-25 \mathrm{Ni}-0.66 \mathrm{C}$.

$\mathrm{Fe}-\mathrm{Ni}-\mathrm{C}$ alloys transformed during cooling. These authors have studied the crossing mechanism of two thin plates considering that the crossing plate deforms plastically (by twinning) the crossed martensite region. Considering one crossed plate, they calculated the resolved shear strain of the 23 possible crossing plates on the $\{112\}<111\rangle_{\text {b }}$ deformation twinning systems in the crossed plate. The largest value of the resolved shear strain is 0 . 21 which is smaller than the value $(0.707)$ for a full twinning in the whole area of the crossed region. From the structural observations in figure 3 it is clear that the substructure in the crossed area consists of a series of couple-domains or full twins distribution. Therefore, the possible mechanism for the formation of the couple - domains is by deformation twinning under internal and external stress. When the plates grow and cross, either some additional twinning occur in the crossed area, or according to Roytburd[7] the domains rearrange themselves in order to relax the internal stresses associated with the transformation strain. These couple - domains $a, b$ and $c$ in plate $B$ can be considered as induced by the $(211)_{b}$ deformation twinning of plate $A$ and the longitudinal twins in these domains were also kinked by the opposite deformation twinning directions. It is further noted that the crossing region of variant $\mathrm{B}$ was converting to the preferred variant $A$ because no contrast of variant $B$ can be found in the DF images. We can also notice that the arrangement of the domains in this crossing area is similar to structures observed by Schroeder and Wayman for reorientation of self accommodating martensites during defomation in $\mathrm{Cu}-\mathrm{Zn}$ alloys [9].

For these changes, one can consider that during deformation, the other variant $B$ can convert to the preferred variant $A$ first by the formation of the couple-domains and then the interfaces of the couple - domains move to connect with the twined domains of plate A 
and finally the $A-B$ junction plane and the plate boundaries are moved by the growth of twinning process until $B$ converts to $A$ completely.

Figure 4(a) shows another type of crossing plates. Three thin plates are connected with a large lenticular plate with full longitudinal twins. These thin plates are like that induced by the growth of twin bands, as shown in figure $2(b)$. From the DF image in figure $4(\mathrm{~b})$, it seems that the thin plates insert into the large plate and are kinked by the longitudinal deformation twins of the large plate.

\subsection{Scanning electron microscopy}

Scanning electron micrographs in figure 5(a) - (c) show another view of the formation mechanism and the characteristics of the deformation - induced compact martensite as mentioned above. Figure 5(a) shows the morphology transition from thin plate to lenticular plate with large twin bands. Figure $5(\mathrm{~b})$ exhibits the coalescence and conversion of different plates. A single orientation of the twin bands in these plates is observed. In figure $5(\mathrm{c})$, we observed the insert of thin plates into large plate in the upper left, the impingement of two plates in the upper right, and the cross of two variants in the middle of the figure. The complex interactions between the plates form a crisscross twinning net. It implied that even though the conversion from other variant to a preferred variant occurred in the compact martensite, it is impossible to convert to a single variant, deformed above Ms .

\section{Conclusions}

The characteristics and formation mechanism of the compact mastensite deformation induced in $\mathrm{Fe}-\mathrm{Ni}-\mathrm{C}$ alloys at low temperatures are as follows :

(1) Compact martensite is formed in some grains during plastic deformation. The compact martensite consists of many martensite plates with different twinned domains connected closely. Its substructure is a crisscross twinning net.

(2) During deformation, the growth and connective modes of the plates are controlled by the martensitic twinning arrangments which lead the plates tending to crossing, insertion, coalescence and conversion.

(3) Other plates convert to preferred plate first by the formation of couple-domains and then the interfaces of the couple-domains move to form deformation twinning bands, and finally convert to a single orientation.

Acknowledgments

This project was financially supported by the National Nature Science Fundation of China (NSFC), Academia Sinica and CNRS France.

References

[1] Zhang X.M., Gautier E. and Simon A., Acta Metall. 17 (1989) $477-485$

[2] Zhang X.M., Gautier E. and Simon A., ibid $487-497$

[3] Zhang X.M., Li D.F., Xing Z.S., Gautier E., Zhang J.S. and Simon A., Acta Metall. Mater. 41(1993) $1693-1699$

[4] Zhang X.M., Li D.F., Zhao S., Xing Z.S., Zhang J.Z., Gautier E., and Simon A., Proc. of ICOMAT - 92, Monterey, Califormia 20-24 July 1992, C. M. Wayman and J. Perkins Eds. pp $493-498$

[5] Gautier E., Zhang J.S., Zhang X.M. and Hu T. R., PTM94' Solid-solid Phase Transformation, Eds. Johnson W. C. et al (TMS 1994) pp

[6] Roytburd A.L. and Kurdjumov G. V., Mat. Sci. and Eng., 39(1979), 141- 167

[7] Roytburd A.L. and Pankova M.N., Phys. Met. Metall. , 59(1985), $131-140$

[8] Okamoto H. , Oka M. and Tamura I., Acta Metall. 27 (1979) 1789-1799

[9] Schroeder T.A. and Wayman C. M. , Acta Metall. 25(1977) 1375 